\title{
Tsafon
}

Revue d'études juives du Nord

$77 \mid 2019$

Contribution à l'histoire des traductions juives de la Bible hébraïque

\section{Judaïsmes européens (1770-1930). Laboratoires des identités partagées, conférence des 5 et 6 mars 2018}

Danielle Delmaire

\section{CpenEdition}

\section{Journals}

Édition électronique

URL : https://journals.openedition.org/tsafon/2158

DOI : 10.4000/tsafon.2158

ISSN : 2609-6420

Éditeur

Association Jean-Marie Delmaire

Édition imprimée

Date de publication : 1 septembre 2019

Pagination : 179-180

ISSN : 1149-6630

\section{Référence électronique}

Danielle Delmaire, « Judaïsmes européens (1770-1930). Laboratoires des identités partagées, conférence des 5 et 6 mars $2018 »$, Tsafon [En ligne], 77 | 2019, mis en ligne le 09 septembre 2019, consulté le 24 juin 2021. URL : http://journals.openedition.org/tsafon/2158 ; DOI : https://doi.org/ $10.4000 /$ tsafon. 2158

Ce document a été généré automatiquement le 24 juin 2021.

Tsafon. Revues d'études juives du Nord 


\title{
Judaïsmes européens (1770-1930). Laboratoires des identités partagées, conférence des 5 et 6 mars 2018
}

\author{
Danielle Delmaire
}

\section{RÉFÉRENCE}

enregistrée et parue en ligne : https://judeuro2018.sciencesconf.org. Durée du documentaire : $1 \mathrm{~h} 16$

1 À cette conférence ont participé une douzaine de spécialistes de l'histoire des communautés juives européennes, certains d'entre eux plus connaisseurs d'un pays (Angleterre, Italie ou Allemagne etc.) d'autres plus érudits sur les fondements du judaïsme ou les penseurs juifs. Il faut reconnaître un savoir faire et une sagacité remarquables pour trier et associer les différentes prises de paroles des conférenciers afin de restituer un ensemble cohérent et bien équilibré. Le montage a dû occasionner des heures de travail.

2 La présentation du documentaire donne à comprendre les intentions des organisateurs : «À quelques semaines des élections européennes et dans un contexte de résurgence de formes marquées d'antisémitisme en France comme sur l'ensemble du continent, le documentaire Judaïsmes européens (1770-1930). Laboratoires des identités partagées propose une relecture de l'histoire contemporaine de l'idée d'Europe à partir du destin des Juifs sur le continent. Il permet également de s'interroger sur le rapport spécifique que les Juifs ont pu construire à l'Europe comme entité culturelle et comme projet politique, depuis le temps des émancipations jusqu'à l'arrivée du nazisme en Allemagne ». L'auditeur n'est pas déçu, il s'agit bien d'entendre l'avis des historiens sur l'influence des juifs dans la mise en place de l'Europe, celle des Lumières au XVIIIe siècle et des 
conséquences de celles-ci sur l'existence des juifs, jusqu'à la veille du triomphe de l'antisémitisme en Europe avec l'expansionnisme de l'Allemagne nazie. Quel rôle les juifs ont joué dans l'Europe moderne et quel impact le libéralisme, politique, économique et social, a eu sur les communautés juives ou les destins d'individus? Sujet d'actualité en effet.

3 L'entrée dans la modernité à la fin du XVIIIe siècle et l'affirmation de la nécessité d'une émancipation bouleverse les communautés où les rabbins voient leur influence diminuer. L'évolution n'est pas générale, elle émerge en Europe occidentale (Allemagne, France, Angleterre) et progresse lentement vers l'est où la Russie reste longtemps rétive à toute émancipation des juifs. En outre, cette libéralisation de la condition des juifs provient des idées révolutionnaires françaises qui, finalement, n'ont pas bonne presse dans les Empires centraux qui connurent l'occupation napoléonienne. La Restauration est une période durant laquelle la régression est générale pour les juifs d'Europe. Il ne faut guère s'étonner, alors, de dénombrer des juifs dans les mouvements libéraux et patriotes favorables à la constitution des nationalités en Europe. Le sionisme n'est-il pas né dans ce contexte et n'est-il pas lui aussi un mouvement de libération nationale?

4 Est souligné également le rôle des juifs dans le développement des sciences, des techniques ainsi que des arts (musique, littérature, peinture) et de la philosophie, voire même de la linguistique avec les efforts de Zamenhof pour mettre en circulation une langue internationale : l'espéranto. Quelques conférenciers vont jusqu'à évoquer leur rôle de passeur entre le judaïsme et le monde moderne. Passeurs aussi furent les fondateurs de l'Alliance israélite universel qui s'attachèrent à répandre dans le Bassin méditerranéen la culture européenne en général et française en particulier.

À rebours, l'émancipation qui devait libérer les juifs des contraintes antisémites suscite dans les milieux conservateurs, surtout à l'est mais même dans les pays de grande culture des Lumières comme l'Allemagne, un antisémitisme qui ravage les communautés d'Europe centrale et orientale. Ces conditions de vie difficiles n'affaiblirent les sentiments patriotiques des juifs : partout les juifs se sont engagés dans le premier conflit mondial pour défendre leur patrie. Ce qui n'empêchait pas les soupçons de traîtrise qu'une partie de la population nourrissait à leur égard.

Le judaïsme européen est multiple dans les années trente du XXe siècle : discret à l'ouest, plus particulier à l'est avec une littérature yiddish brillante. C'est ce monde qui est menacé à la veille de la Seconde Guerre mondiale.

7 L'écoute de cette conférence est enrichissante même si elle n'apporte pas d'innovation majeure dans nos connaissances. Des documents illustrent les interventions des conférenciers que l'on voit dans une posture un peu trop statique, mais il faut remercier V. Vilmain d'avoir réussi à rassembler une douzaine de collègues pour les inviter à s'exprimer sur tous ces sujets.

8 Étaient réunis : F. Abecassis, D. Bourel, J. Ehrenfreund, S-A Goldberg, J. Guedj, C. Le Foll, M. Michaud, C. Nicault, S. Nordmann, J-P Schreiber, E. Touboul, V. Vilmain. 